\title{
Anthropogenic waste indicators (AWIs), particularly PAHs and LABs, in Malaysian sediments: application of aquatic environment for identifying anthropogenic pollution
}

\begin{abstract}
Polycyclic aromatic hydrocarbons (PAHs) and linear alkylbenzenes (LABs) were used as anthropogenic markers of organic chemical pollution of sediments in the Selangor River, Peninsular Malaysia. This study was conducted on sediment samples from the beginning of the estuary to the upstream river during dry and rainy seasons. The concentrations of IPAHs and ILABs ranged from 203 to 964 and from 23 to $113 \mathrm{ng}$ gī 1 dry weight (dw), respectively. In particular, the Selangor River was found to have higher sedimentary levels of PAHs and LABs during the wet season than in the dry season, which was primarily associated with the intensity of domestic wastewater discharge and high amounts of urban runoff washing the pollutants from the surrounding area. The concentrations of the toxic contaminants were determined according to the Sediment Quality Guidelines (SQGs). The PAH levels in the Selangor River did not exceed the SQGs, for example, the effects range low (ERL) value, indicating that they cannot exert adverse biological effects.
\end{abstract}

Keyword: Polycyclic aromatic hydrocarbons (PAHs); Linear alkylbenzenes (LABs); Molecular marker; Anthropogenic inputs; Source identification; Selangor river 